\title{
Design of Confectionery Slicer for SME's Product Quality Improvement
}

\author{
Sri Indrawati, Tio Sampurno, Yogi Thanjaya, and Rahmadani R. Octaviani
}

\begin{abstract}
Managing product quality is crucial for small and medium enterprises. Customer satisfaction and loyalty will be maintained by quality products. In order to improve the quality of product, this research is conducted to develop a confectionery slicer for a small and medium enterprise using quality function deployment. The first stage in this research is doing a customer survey to determine the customer needs and their priorities in processing the product. The customers for this research are SME's SB workers. Then a data verification using statistics is done and subsequently used to develop confectionery slicer. The prioritized technical specifications of the product based on design deployment matrix formulation are size of the blade, blade number, level of mechanization, the distance between blades, the quality test and blade materials. The research proves that the developed concept of confectionery slicer is able to improve the quality and productivity of SME's products.
\end{abstract}

Index Terms-Product design, QFD, product quality improvement, small and medium enterprises.

\section{INTRODUCTION}

Highlight The success of a new product depends on the superior products quality than competitors [1]. Superior advantages of a product and the communication process effectiveness within the manufacturers to provide information about some advantages for customers becomes a major factor. This indicates that the manufacturers also need a strategy for improving product quality in order to get a good level of acceptance in the market.

Customers needs become the focus of consideration in designing quality products. They will choose the product with the various considerations to obtain satisfaction through some factors such as product functionality and product value [2], [3]. There are several factors such as weight, size, color and shape can affect the quality of the product [4]. The results of these studies indicate that customers` response to product quality are varying between customers. The other research also stated that physical appearance of a product which consists of shape and color are considerable factors affecting the customers' perceived quality [5].

One of the industries that are required to continuously improve the product quality as a result of the dynamic market needs is food manufacturing industry. SME 's SB is a small and medium enterprise that process dairy products such as milk candy. Majority of the production process is based on orders from customers. But sometimes SME 's SB also provide a stock of products for sale in the cooperative. Total average production of at least 100 packs/month.

Manuscript received December 12, 2013; revised February 17, 2014

The authors are with the Industrial Engineering Department, Faculty of Industrial Technology, Universitas Islam Indonesia (corresponding author's e-mail: sriindrawati@uii.ac.id).
In its manufacturing department, some conventional production equipment are used. In the final stages which consist of finishing and packaging process is done by slicing candy with a size of $1 \times 1 \mathrm{~cm}$ using a knife manually. This leads to the milk candy quality of dimensions problem. Though the dimensions and shape of milk candy is one of the quality standards that must be fulfilled. Based on that condition, SME's SB need a confectionery slicer product that is capable of producing $\mathrm{s}$ milk candy dimension in accordance with the quality standards.

There are some methods that can be used to design a product. Quality function deployment (QFD) is one method which has been broadly accepted by manufacturing industries to develop a new product based on customers need [6]. Many Researchers has studied and documented their analysis on quality function deployment application. QFD is a useful technique for the development of the food trolley in India. Major customer needs such as handles for usability, modular shelves design, ergonomics and aesthetics were satisfied by the final design [7]. QFD is also an integrated approach for modeling some important design characteristic of the product office chair in an office environment based on product and customers interaction [8].

Customer satisfaction between the current and the new design of the computer works station that developed using QFD was found significantly increased. The new computer work station designed and developed based on some factors such as durability, assembly, attractiveness, additional features, shape, size, ease of cleaning, functionality and quality of the materials [9]. This can occur because of QFD has the ability to translate several customer complaints into the technical characteristics of the product to produce a design that fulfilled the customers need [10].

Based on the above conditions, this research is being conducted to make confectionery slicer design product that can produce an accurate milk candy dimensions corresponding with quality standard. The method used in the product development is the quality function deployment method. So it is expected that the design of confectionery slicer product can fulfilled the user needs and improve product quality of SME's SB.

\section{BASIC THEORY}

\section{A. Quality Function Deployment (QFD)}

Quality function deployment is an approach in product development that focuses on customer needs [11]. Customers will not be satisfied on a product that is produced when the customer does not want or need it. QFD is designed to help product designer to focus on product characteristics from market segmentation point of view, companies, or the need 
for technological development. QFD is also very useful for transforming the voice of customer (VOC) into the technical specification for a product by prioritizing the characteristics of each product along with the target setting simultaneously [12]. So that product designers can prioritize the customers needs, finding innovative responses to those needs and improve processes to achieve maximum effectiveness. In QFD methodology, there are four types of stages, namely [13]:

1) House of Quality, is a matrix that serves to convert the voice of the customer directly to the products technical requirements or technical specifications that will be produced. Using the technical specification weight, the product development team can focus more on technical characteristics which have a high response in meeting the needs of customers. The technical specification weight is obtained by the following equation [7]:

$$
B_{j}=\sum_{i=1}^{n} K_{i j} H_{i}
$$

where,

$J=$ row vector of weights for technical specification

$(j=1, \ldots, m)$

$K_{i j}=$ weight indicated by the relationship matrix

$(i=1, \ldots, n, j=1, \ldots, m)$

$H_{i}=$ column vector of customers needs weight

$(i=1, \ldots, n)$

$m=$ number of technical specification

$n=$ number of customers specification

2) Part Deployment, the house of quality matrix is brought into this matrix to determine the characteristics of quality parts.

3) Process Deployment, operation process quality characteristic is determined in this step using the previous part of the matrix.

4) Manufacturing /Production Planning, a prototype production of a product launch is done in this final step.

\section{B. Validity Test}

Validity test is a test that being used to measure the research questionnaire's validity, whether it have a correct conceptual framework and measure the same aspect or not. Validity coefficients can be found using the product moment formula persons [14]:

$$
r_{x y}=\frac{N \sum X Y-\left(\sum X\right)\left(\sum Y\right)}{\sqrt{\left(N \sum X^{2}-\left(\sum X\right)^{2}\right)\left(N \sum Y^{2}-\left(\sum Y\right)^{2}\right)}}
$$

where,

$r_{x y}=$ validity coefficient

$N=$ number of samples

$X=$ score attributes indicate scores of each respondent attributes

$Y=$ score attributes indicate scores of each respondent

A measuring instrument is valid if the validity coefficient of each attribute value is greater than the value of $r$ in the $r$ product moment person table.

\section{Reliability Test}

Reliability test is used to determine the consistency of measuring instruments [15]. Reliability of measurement can be done with this following formula:

$$
\begin{gathered}
r x x^{\prime} \geq \alpha=2\left[1-\frac{s_{1}^{2}+s_{2}^{2}}{s_{x}^{2}}\right] \\
s_{1}{ }^{2}=\frac{\sum Y_{1}^{2}-\left(\sum Y_{1}\right)^{2} / N}{N-1} \\
s_{2}{ }^{2}=\frac{\sum Y_{2}^{2}-\left(\sum Y_{2}\right)^{2} / N}{N-1} \\
s_{x}{ }^{2}=\frac{\sum X^{2}-\left(\sum X\right)^{2} / N}{N-1}
\end{gathered}
$$

where,

$$
\begin{aligned}
& r x x^{\prime} \text { ' }=\text { coefficient of reliability } \\
& s_{1}{ }^{2}=\text { variance score of part } 1 \\
& s_{2}{ }^{2}=\text { variance score of part } 2 \\
& s_{x}{ }^{2}=\text { variance score of each respondent } \\
& Y_{1}=\text { total score attribute in group / part } 1 \\
& Y_{2}=\text { total score attribute on the group / part } 2 \\
& X=\text { total score of each respondent on charging item-item } \\
& N=\text { number of samples }
\end{aligned}
$$

\section{CONCEPTUAL WORK}

This research phase contains steps that begin with collecting the data, analyzing and interpreting the results of the data processing with quality function deployment method. The first stage in this research is the customer survey to determine the customer needs and their priorities in processing the milk candy. The customer for this research is SME's SB workers that consist of eight persons. The data were then verified with statistics and subsequently used to calculate the priority needs. Further, technical characteristics and its priority is determined and used for confectionery slicer development.

\section{RESUlT AND DisCUSSION}

\section{A. Use Validity Test}

Based on data calculations, it can be concluded that the existing questionnaire items are valid because the validity coefficient of each attribute value is greater than the value of $r$ in the table $r$ product moment person or $r x y \geq 0.707$.

\section{B. Reliability Test}

The reliability coefficient obtained through selection of items based on the value of validity on each attributes, is equal to 0.82 . This is indicates that the measuring instruments used in this study have a good reliability.

\section{Development of Confectionery Slicer}

Based on customers' survey, $83 \%$ of respondents expressed interest in confectionery slicer products that will be developed. The customers' survey also provides some identified customer needs as shown in Table I.

The customer value's importance rating in Table I, indicates that according to customers, some factors that give a high interest rate on this confectionery slicer products are non-sticky, the size and stability of the resulting size of the candy. It is considered very important because it relates to the products quality of milk candy that being produced. While at 
level two, some factors that categorized as important for confectionery slicer is ease of use and energy efficient products. Attributes considered ease of use is important because it relates to the simplicity in operation.

The customer needs which considered as important and very important is a basic consideration of the development of confectionery slicer's product specification. While the products specifications that become a focus of development is indicated with technical weight and priority order as shown in Table II. There are six priorities of product specifications, namely: the size of blades, number of blades, the level of mechanization, the distance between blades, the test quality and blade materials.
TABLE I: CUSTOMER NEEDS OF CONFECTIONERY SLICER

\begin{tabular}{lll}
\hline No. & \multicolumn{1}{c}{ Needs } & $\begin{array}{c}\text { Importance } \\
\text { Rating }\end{array}$ \\
\hline 1 & The price of the product & 2 \\
2 & Security & 3 \\
3 & Ease of use & 4 \\
4 & Ease of maintenance & 3 \\
5 & Non sticky & 5 \\
6 & The resulting candy size & 5 \\
7 & The stability of the & 5 \\
8 & resulting candy size & 3 \\
9 & Attractive External & 4 \\
\hline & appearance & 3 \\
\hline \hline
\end{tabular}

TABLE II: TECHNICAL SPECIFICATIONS OF CONFECTIONERY SLICER

\begin{tabular}{|c|c|c|c|c|c|c|c|}
\hline $\begin{array}{l}\text { No. } \\
\text { Metrics }\end{array}$ & No. Needs & Technical Specification & $\begin{array}{l}\text { Technical } \\
\text { Weight }\end{array}$ & $\begin{array}{l}\text { Priority } \\
\text { Order }\end{array}$ & Unit & $\begin{array}{l}\text { Direction of } \\
\text { Goodness }\end{array}$ & Value \\
\hline 1 & $3,4,8$ & Dimensions of the product & 32 & 7 & $\mathrm{~cm}$ & o & $5,7 \times 15 \times 23$ \\
\hline 2 & 3,4 & The total weight of the product & 21 & 10 & $\mathrm{~kg}$ & $\downarrow$ & $<0,5$ \\
\hline 3 & $1,2,6,7$ & The size of the blade & 65 & 2 & $\mathrm{~mm}$ & $\circ$ & D 52,42 \\
\hline 4 & $1,2,6,7,11$ & Number of blades & 65 & 2 & number & $\uparrow$ & 3 \\
\hline 5 & $1,2,3,4,9,10$ & The level of mechanization & 71 & 1 & list & $\circ$ & manual \\
\hline 6 & $1,5,7$ & Blade materials & 46 & 5 & list & $\uparrow$ & $\begin{array}{l}\text { stainless } \\
\text { steel }\end{array}$ \\
\hline 7 & $1,2,3$ & Handle materials & 33 & 6 & list & $\circ$ & $\begin{array}{l}\text { soft kraton } \\
\text { rubber }\end{array}$ \\
\hline 8 & 3,11 & Set up time production & 16 & 11 & minute & $\downarrow$ & $<5$ \\
\hline 9 & 6,7 & Quality test pieces & 50 & 4 & binary & $\uparrow$ & pass \\
\hline 10 & 2,10 & Noise test & 24 & 9 & $\mathrm{~dB}$ & $\downarrow$ & pass \\
\hline 11 & $2,3,4$ & $\begin{array}{l}\text { The distance between the } \\
\text { blade and handle }\end{array}$ & 30 & 8 & $\mathrm{~cm}$ & $\uparrow$ & 20 \\
\hline 12 & $6,7,11$ & The distance between blades & 62 & 3 & $\mathrm{~cm}$ & $\circ$ & 1 \\
\hline 13 & 4,8 & Form of product & 24 & 9 & subj. & $\circ$ & standard \\
\hline 14 & 8 & Color of products & 15 & 12 & subj. & $\circ$ & standard \\
\hline
\end{tabular}

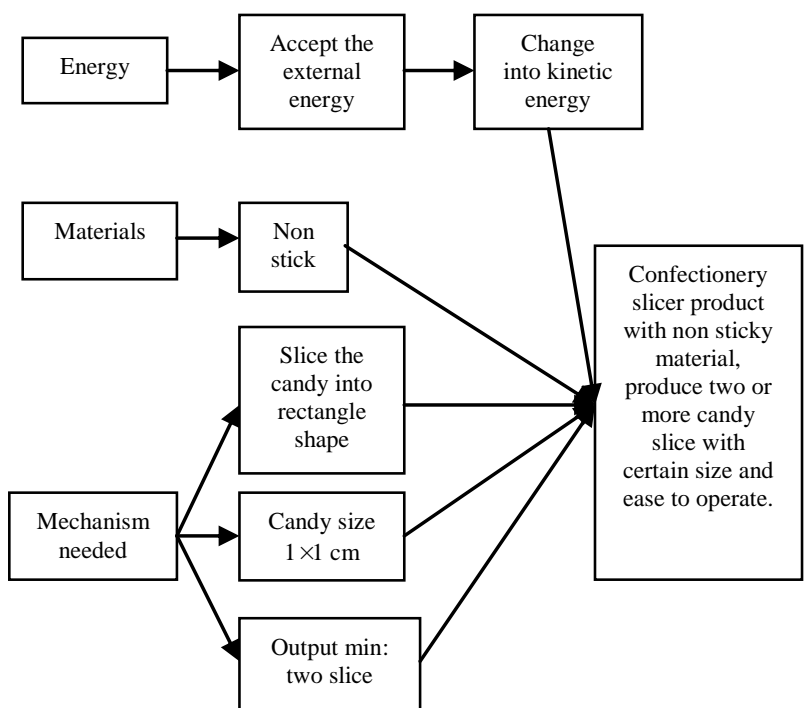

Fig. 1. Problem's decomposition of confectionery slicer product.

\begin{tabular}{|c|c|c|}
\hline No. & $\begin{array}{l}\text { Type of } \\
\text { Concept }\end{array}$ & Specification \\
\hline 1 & $\mathrm{~A}$ & $\begin{array}{l}\text { Electricity energy, stainless steel } \\
\text { blades, stamp mechanism }\end{array}$ \\
\hline 2 & B & $\begin{array}{l}\text { Electricity energy, stainless steel } \\
\text { blades, slicer mechanism }\end{array}$ \\
\hline 3 & $\mathrm{C}$ & $\begin{array}{l}\text { Manual, stainless steel blades, stamp } \\
\text { mechanism }\end{array}$ \\
\hline 4 & $\mathrm{D}$ & $\begin{array}{l}\text { Manual, stainless steel blades, slicer } \\
\text { mechanism }\end{array}$ \\
\hline
\end{tabular}

Fom that technical specification list, the confectionery slicer product's problem that occurs can be decompossed as shown in Fig. 1.

The confectionery slicer product's accept the external energy to perform it's main function. It should produce two slice of candy in rectangle shape with a certain size. To improve the candy quality, it should be non sticky and easy to be operated. After identifying the problem decomposition, some feasible concept for confectionery slicer product are developed. The result of concept generation can be seen in Table III.

\section{TABLE IV: CONCEPT SCREENING OF CONFECTIONERY SLICER}

\begin{tabular}{ccccc}
\hline \hline Criteria & \multicolumn{5}{c}{ Type of Concept } \\
& A & B & C & D \\
\hline Energy efficiency & - & - & + & + \\
Easy to operate & 0 & 0 & 0 & 0 \\
Output quality & 0 & + & 0 & + \\
Noise & - & - & + & + \\
Price & - & - & + & + \\
\hline Sum +'s & 0 & 1 & 3 & 4 \\
Sum 0's & 2 & 1 & 2 & 1 \\
Sum -'s & 3 & 3 & 0 & 0 \\
\hline Net Score & -3 & -2 & 3 & 4 \\
Rank & 4 & 3 & 2 & 1 \\
Continue? & no & no & no & yes \\
\hline \hline
\end{tabular}


There are four alternative of product development concept that should be selected. Concept screening is used in this step with the result shown in Table IV.

The alternative design concept is compared based on six criteria from customers importance need. Positive score means the design concept strength. Zero score indicated that the design concept perform a standard score compared with others. While negative score means the design concept weakness. And the highest net score then being selected as confectionery slicer products that will be produced.

The confectionery slicer products concept that being developed is used manually so it is easy to operate, efficient in energy and does not cause some noise. This product has the size and space between the blades that adapted from milk candy dimensions that around $1 \times 1 \mathrm{~cm}$. So it can increase the stability of the milk candy size based on quality standards. Stainless steel is chosen as the confectionery slicer's blades to prevent a sticking to the dough candy milk. For product dimensions are determined using anthropometry method that can support the ease and comfort during the manufacturing process. Overall external appearance of confectionery slicer products can be seen in Fig. 2.

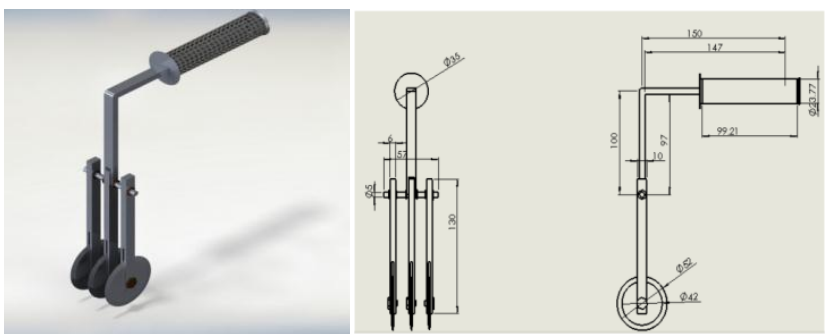

Fig. 2. Results product development confectionery slicer.

\section{CONCLUSION}

Based on the research that have been conducted on confectionery slicer products, it can be concluded that the product characteristics which considered as an important and very important for the users are non-stick, the size and stability of the resulting candy size, ease of use and energy-saving products. While the primary technical specifications of the design deployment matrix are the blade size, number of blade, level of mechanization, the distance between the blades, the quality test and blade materials. The design concept of confectionery slicer products that have been developed with QFD method is able to improve the quality and productivity of milk candy products of SME's SB.

\section{ACKNOWLEDGMENT}

Researcher thank to the support of Manufacturing System Laboratory, Industrial Engineering Department, Universitas Islam Indonesia.

\section{REFERENCES}

[1] D. Unger and S. Eppinger, "Improving product development process design: A method for managing information flows, risks and iteration", International Journal of Engineering Design, vol. 22, pp. 10, 2011.

[2] M. R. Shaharudin, S. W. Mansor, A. A. Hassan, and M. W. Omar, "The relationship between product quality and purchase intention: The case of Malaysia's national motorcycle/ scooter manufacturer," African Journal of Business Management, vol. 5, pp. 8163-8176, 2011.
[3] O. Chadha, "Study of customer buying behavior towards bikes," International Journal of Research in Finance and Marketing, vol. 1. 2011.

[4] V. Harrar and C. Spence, "How the taste of food is affected by weight, size, shape and color of product," Flavour Journal, vol. 2, pp. 1-12, 2013.

[5] S. Indrawati, "Quality dimension analysis for indonesian national motorcycle innovation," Operation Research and Statistics Proceeding, vol. 1, pp 86-91, 2013.

[6] H. Kaebernick, L. E. Farmer, and S. Mozar, "Concurrent product and process design," The University of New South Wales, 1996.

[7] N. P. Anuraj, Srinivasa, and V. Ravichandran, "Design of a food trolley for hospital India," SASTECH Journal, vol. 12, pp. 90-98, 2013.

[8] P. P. Mohanty and S. S. Mahaptra, "Design of office chair: A quality function deployment approach," Journal of Advanced Materials Manufacturing and Characterization, vol. 3, pp. 520-523, 2013.

[9] C. M. Annappa and K. S. Panditrao, "Integration of quality function deployment and value engineering in furniture manufacturing industry for improvement of computer work station," International Journal of Innovative Technology and Exploring Engineering, vol. 2, pp. 45-52, 2013.

[10] R. Fatima, D. A. Rahmaniyah, and I. Pridythama, "Traditional medicine packaging design using quality function deployment," Sains and Technology Apllication Proceeding, vol. 1, pp. 129-135, 2012.

[11] K. T. Ulrich and S. D. Eppinger, Product Design and Development, McGraw-Hill Inc., Singapore, 1995.

[12] L. Cohen, Quality function deployment: How to make QFD work for you, Prentice Hall, 1995.

[13] J. Terninko, Step by step QFD: Customer driven product design, CRC Press, 1997.

[14] S. Azwar, Reliability and validity, Pustaka Pelajar, Yogyakarta, 2006.

[15] Sugiyono, Administration research methodology, Alfabeta, Bandung, 2007.

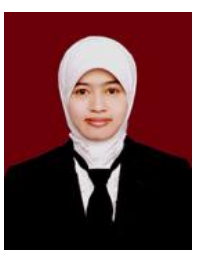

Sri Indrawati was born on January 18, 1986 in Yogyakarta, Indonesia. She is a lecturer and the head of Manufacturing System Laboratory at Department of Industrial Engineering, Faculty of Industrial Technology, Universitas Islam Indonesia, Indonesia. She received a master degree from the Department of Industrial Engineering, Gadjah Mada University, Indonesia in 2009. Her teaching and research interests include product development strategy and manufacturing performance improvement.

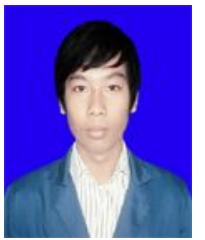

Tio Sampurno was born on September 12, 1991 in Palembang, Indonesia. $\mathrm{He}$ is an assistant of Manufacturing System Laboratory and now studying at Department of Industrial Engineering, Faculty of Industrial Technology, Universitas Islam Indonesia, Indonesia. His research interests are product design innovation.

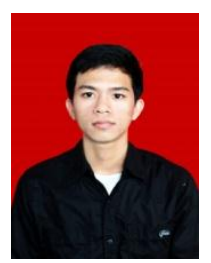

Yogi Thanjaya was born on July 31, 1993 in Pagar Alam, Indonesia. He is an assistant of Manufacturing System Laboratory and now studying at Department of Industrial Engineering, Faculty of Industrial Technology, Universitas Islam Indonesia, Yogyakarta, Indonesia. His research interests is product design development

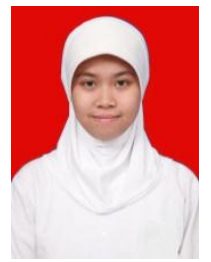

Rahmadani R. Octaviani was born on March 16, 1992 in Boyolali, Indonesia. She is an assistant of Manufacturing System Laboratory and now studying at Department of Industrial Engineering, Faculty of Industrial Technology, Universitas Islam Indonesia, Yogyakarta, Indonesia. Her research interests are product design and production process improvement. 